\title{
UPAYA MENINGKATKAN SIKAP PERCAYA DIRI DAN PRESTASI BELAJAR IPA MATERI PENGARUH PERUBAHAN LINGKUNGAN FISIK TERHADAP DARATAN MELALUI MODEL PEMBELAJARAN QUANTUM
}

\author{
Susi Susanti \\ SD Negeri 2 Sudagaran, Banyumas, Indonesia \\ Email: susisusantieva13@yahoo.com
}

\begin{abstract}
The student's low self-confidence and learning achievement became the main problem in class IV SD Negeri 2 Sudagaran Banyumas. Some factors causing the low confidence and learning achievement were that the learning was still conventional; the students were not active during the lesson. The research was conducted as the solution using quantum learning model. This was a classroom action research with two cycles consisting of planning, acting, observing, and reflecting. The result of the research showed that quantum learning model could improve the student's confidence and learning achievement for the fourth graders of SD Negeri 2 Sudagaran Banyumas. It could be proven by the improvement of the student's questionnaire got improvement, it was 73,48\% in cycle I on in enough criteria and 77,28\% in cycle II or in good criteria. The result of the students' learning mastery also got improvement, it was $78,27 \%$ in cycle I or in good criteria and $86,96 \%$ in cycle II or in very good criteria. Based on the result of this classroom action research conducted in two cycle, it could be concluded that quantum learning model could improve the students' confidence and learning achievement on science on topic of The Effect of Physically Environment change for the fourth graders of SD Negeri 2 Sudagaran Banyumas.
\end{abstract}

Keyword : self-confidence, learning achievement, quantum learning model.

Abstrak. Rendahnya rasa percaya diri dan prestasi belajar siswa menjadi masalah utama di kelas IV SD Negeri 2 Sudagaran Banyumas. Beberapa faktor yang menyebabkan rendahnya kepercayaan diri dan prestasi belajar adalah bahwa pembelajaran itu masih konvensional; siswa tidak aktif selama pelajaran. Penelitian ini dilakukan sebagai solusi menggunakan model pembelajaran kuantum. Ini adalah penelitian tindakan kelas dengan dua siklus yang terdiri dari perencanaan, tindakan, pengamatan, dan refleksi. Hasil penelitian menunjukkan bahwa model pembelajaran kuantum dapat meningkatkan kepercayaan diri siswa dan prestasi belajar untuk siswa kelas empat SD Negeri 2 Sudagaran Banyumas. Hal ini dapat dibuktikan dengan peningkatan angket siswa mendapat peningkatan, yaitu $73,48 \%$ pada siklus I pada kriteria cukup dan $77,28 \%$ pada siklus II atau dalam kriteria baik. Hasil penguasaan belajar siswa juga mengalami peningkatan, yaitu 78,27\% pada siklus I atau dalam kriteria baik dan $86,96 \%$ pada siklus II atau dalam kriteria sangat baik. Berdasarkan hasil penelitian tindakan kelas yang dilakukan dalam dua siklus, dapat disimpulkan bahwa model pembelajaran kuantum dapat meningkatkan kepercayaan diri siswa dan prestasi belajar pada sains pada topik Pengaruh Perubahan Lingkungan Fisik untuk siswa kelas empat SD Negeri 2. Sudagaran Banyumas.

Kata kunci: kepercayaan diri, prestasi belajar, model pembelajaran kuantum.

\section{PENDAHULUAN}

Ilmu Pengetahuan Alam sangat diperlukan dalam kehidupan sehari-hari untuk memenuhi kebutuhan manusia melalui pemecahan masalah-masalah yang dapat diidentifikasikan. Penerapan Ilmu Pengetahuan Alam perlu dilakukan secara baik dan bijaksana agar tidak berdampak buruk terhadap lingkungan sekitarnya. Ditingkat SD/MI diharapkan ada penekanan 
pembelajaran yang diarahkan pada pengalaman belajar siswa secara langsung untuk merancang dan membuat suatu karya melalui penerapan konsep dasar IPA dan kompetensi bekerja ilmiah secara bijaksana.

Pendidikan IPA diharapkan dapat menjadi tempat bagi peserta didik untuk mempelajari apa yang ada dalam dirinya sendiri dan lingkungan alam yang ada disekitarnya. Proses pembelajaran IPA menekankan pada pemberian pengalaman langsung untuk mengembangkan kompetensi yang dimiliki sehingga dapat memahami alam sekitar secara ilmiah dan bijaksana. Karena hal tersebut, diharapkan guru dapat membantu siswanya untuk dapat memahami materi pelajaran IPA dengan baik agar tidak terjadi kesalahan konsep sehingga terdapat kekeliruan yang nantinya dapat mempengaruhi siswa dalam menerapkan konsep yang benar pada kehidupan sehari-hari.

Rendahnya sikap percaya diri dan kemauan belajar siswa kelas IV SD Negeri 2 Sudagaran ditunjukan dengan kurangnya keaktifan siswa untuk mengajukan pertanyaan kepada guru atau temannya, kurangnya kemauan siswa untuk maju kedepan kelas, dan kurangnya perhatian guru terhadap siswa pada saat proses pembelajaran. Permasalahan tersebut harus segera diatasi dengan berbagai cara agar tidak berkelanjutan dan untuk mengurangi terjadinya berbagai kerugian. Untuk itu pembelajaran dilakukan dengan menggunakan model pembelajaran quantum untuk membantu siswa dalam meningkatkan sikap percaya diri dan prestasi belajar IPA siswa kelas IV SD Negeri 2 Sudagaran Banyumas. Permasalahan tersebut dibuktikan dari hasil data ulangan harian pada mata pelajaran tersebut, kemudian melakukan observasi dan wawancara terhadap guru dan siswa.

\section{METODE PENELITIAN}

Penelitian ini dilaksanakan di kelas IV SD Negeri 2 Sudagaran Kecamatan Banyumas Kabupaten Banyumas. Siswa kelas IV SD Negeri 2 Sudagaran Banyumas terdiri dari 25 siswa yaitu 10 siswa lakilaki dan 15 siswa perempuan. Dalam penelitian ini, peneliti berkolaborasi dengan guru kelas IV. Penelitian yang digunakan yaitu Penelitian Tindakan Kelas (PTK) yang terdiri dari dua siklus.Setiap siklus terdiri dari dua kali pertemuan yang terdiri dari perencanaan, tindakan, pengamatan, dan refleksi. Setiap pertemuan pada satu siklus terdiri dari kegiatan awal, kegiatan inti dan kegiatan akhir. Pembelajaran yang dilaksanakan pada setiap pertemuan menggunakan model pembelajaran quantum . Data yang diperoleh dalam penelitian ini yaitu data observasi sikap percaya diri yang diambil dari lembar angket, dan prestasi belajar siswa peneliti menggunakan lembar evaluasi yaitu berupa 5 butir uraian. Data aktivitas guru diperoleh dengan menggunakan lembar aktivitas guru selama guru melakukan proses pembelajaran sedangkan data aktivitas siswa diperoleh dari hasil observasi aktivitas siswa selama proses pembelajaran berlangsung.

\section{HASIL PENELITIAN DAN PEMBAHASAN}

Penelitian dilaksanakan pada semester 2 akhir tahun pelajaran 2013/2014. Adapun hasil sikap percaya diri dan prestasi belajar ipa melalui model pembelajaran quantum yang diperoleh 
pada siklus 1 dan siklus 2 dapat dilihat pada

tabel berikut :

Tabel 1.

Rekapitulasi Hasil Angket Sikap Percaya Diri

\begin{tabular}{|l|l|l|l|}
\hline SIKLUS & JUMLAH & PRESENTASE & KRITERIA \\
\hline 1 & 676 & $73.48 \%$ & CUKUP \\
\hline 2 & 711 & $77.28 \%$ & BAIK \\
\hline
\end{tabular}

Rekapitulasi hasil angket sikap yaitu pada siklus 1 dengan presentasi 73.48 percaya diri pada tabel diatas, dapat dilihat $\%$ meningkat menjadi $77.28 \%$ pada siklus bahwa se;ama proses pembelajaran dari 2 . siklus 1 ke siklus 2 mengalami peningkatan

Tabel 2.

Rekapitulasi Hassil Prestasi Belajar IPA

\begin{tabular}{|l|l|}
\hline Jumlah siswa & 23 anak \\
\hline Nilai $<65$ & 18 anak \\
\hline Nilai $>65$ & 5 anak \\
\hline Tidak tuntas & $78.27 \%$ \\
\hline Tuntas & $21.74 \%$ \\
\hline $\begin{array}{l}\text { Ketuntasan secara klasikal } \\
\text { (SIKLUS 1) }\end{array}$ & Belum mencapai indikator keberhasilan \\
\hline Jumlah siswa & 23 anak \\
\hline Nilai $<65$ & 3 anak \\
\hline Nilai $>65$ & 20 anak \\
\hline Tidak tuntas & $13.04 \%$ \\
\hline Tuntas & $86.95 \%$ \\
\hline Ketuntasan secara klasikal \\
(SIKLUS 2) & Sudah mencapai indikator keberhasilan \\
\hline
\end{tabular}

Rekapitulasi hasil prestasi belajar IPA pada Table 2 di atas dapat dilihat bahwa selama proses pembelajaran mengalami peningkatan dari siklus 1 ke siklus 2 . Dengan presentase siswa yang tuntas 21.74 $\%$ meningkat menjadi $86.95 \%$.

Peneliti melakukan observasi terhadap guru dan siswa selama proses pembelajaran dengan menggunakan lembar observasi aktivitas guru dan siswa.. Observasi aktivitas siswa yang dilakukan selama proses pembelajaran mengalami peningkatan yaitu dengan presentase $75 \%$ dengan kriteria cukup pada siklus 1 meningkat pada siklus 2 dengan presentase $79.5 \%$ dengan kriteria baik. Pada aktivitas siswa juga mengalami peningkatan yaitu dengan presentasi 71.7 pada siklus 1 meningkat menjadi 78.2 dengan kriteria cukup pada siklus 2 dengan kriteria baik.

\section{SIMPULAN DAN SARAN}

Berdasarkan dari hasil penelitian yang telah dipaparkan diatas, diperoleh kesimpulan bahwa sikap percaya diri dan prestasi belajar IPA siswa kelas IV SD Negeri 2 Sudagarn Banyumas dapat meningkat melalui proses pembelajaran menggunakan model pembelajaran quantum. Selain adanya peningkatan sikap percaya diri dan prestasi belajar IPA, aktivitas guru dan siswa juga meengalami peningkatan.

Saran dalam penelitian ini yaitu sebaiknya guru dapat meemanfaatkan waktu sebaik-baiknya agar penerapan model pembelajaran quantum dapat 
terlaksana dengan baik, selain itu guru juga lebih aktif membantu dan mengamati siswa saat proses pembelajaran berlangsung.

\section{DAFTAR PUSTAKA}

Arikunto, S, dkk. (2012). Penelitian Tindakan Kelas. Jakarta: PT Bumi Aksara.

Elfindri, dkk.(2012). Pendidikan Karakter Kerangka, metode, dan aplikasi untuk pendidikan dan professional. Jakarta: Baduose Media Jakarta.

Gredler, M.E. (2011). Learning and instructions teori dan aplikasi. Jakarta: Prenada Media Group. Hergenhanh, M.H.O. (2010). Theories Of Learning. Jakarta: Prenada Media Group.

Mustari, M. (2011).Nilai Karakter Refleksi untuk Pendidikan Karakter. Jakarta: LaksBang PRESSindo 